\title{
A Rapid, Validated RP-HPLC Method for the Determination of Seven Volatile $\mathrm{N}$-Nitrosamines in Meat
}

\author{
Mohammad Al-Kaseem"1, Zaid Al-Assaf' ${ }^{1}$, François Karabeet ${ }^{2}$ \\ ${ }^{1}$ Department of Analytical and Food Chemistry, Faculty of Pharmacy, Damascus University, Damascus, Syria \\ ${ }^{2}$ Department of Chemistry, Faculty of Science, Damascus University, Damascus, Syria \\ Email: mkaseem74@gmail.com
}

Received 19 December 2013; revised 22 February 2014; accepted 14 March 2014

Copyright (C) 2014 by authors and Scientific Research Publishing Inc.

This work is licensed under the Creative Commons Attribution International License (CC BY). http://creativecommons.org/licenses/by/4.0/

(c) (i) Open Access

\section{Abstract}

The present work reports a rapid reversed-phase high-performance liquid chromatography (RP-HPLC) method for the determination of seven volatile $\mathrm{N}$-nitrosamines namely $\mathrm{N}$-nitrosodimethylamine (NDMA), N-nitrosomethylethylamine (NMEA), N-nitrosodiethylamine (NDEA), N-nitrosodiproylamine (NDPA), N-nitrosodi butylamine (NDBA), N-nitrosopiperidine (NPIP) and $\mathrm{N}$-nitrosopyrrolidine (NPYR) for monitoring food safety. A strategic experimental approach was implemented for the method development. The desired chromatographic separation was achieved on a Symmetry C18 $(4.6 \times 150 \mathrm{~mm}, 5 \mu \mathrm{m})$ column using gradient elution. The optimized mobile phase consisted of the $10 \mathrm{mM}$ ammonium hydroxide $\mathrm{pH}=8.9$ and acetonitrile. The eluted compounds were monitored at $231 \mathrm{~nm}$ wavelength using spectrophotometric detector. The developed method separated seven compounds from each other within a run time of $10 \mathrm{~min}$. The method is effective for the determination of presence of these carcinogenic compounds. The average extraction recovery of seven nitrosamines was found 84.5\%; the precision of method was found less than $2.7 \%$ and accuracy was found between $95 \%-102.5 \%$. The assay could be applied in food monitoring safety.

\section{Keywords}

N-Nitrosamines; Rp-HPLC; Food Safety

\section{Introduction}

Nitrosamines form a large group of genotoxic chemical carcinogens which occur in the human diet and other 
environmental media [1] [2], and can be formed endogenously in the human body [3]. N-nitroso compounds can induce cancer in experimental animals [4]. In foods, nitrosamines are produced from nitrites and secondary amines, which often occur in the form of proteins [5]. Their formation can occur only under certain conditions, including strongly acidic conditions such as that of the human stomach [6]. High temperatures, as in frying, can also enhance the formation of nitrosamines. These processes lead to significant levels of nitrosamines in many foodstuffs [7], especially beer [8], fish, and fish byproducts [9], and also in meat and cheese products preserved with nitrite pickling salt [10]. Nitrosamines can also be found in tobacco smoke, cosmetics, pesticides, and in most rubber products [11] [12]. There are a great number of scientific papers reported in the literature on the presence of volatile nitrosamines in food matrices. In general, these methods recommend the extraction of nitrosamines from the food matrix by extraction methods, including distillation (steam, vacuum, or atmospheric) [13]-[15], solvent extraction [1], solid-phase extraction [16], solid-phase micro-extraction (SPME) [17], autoclave extraction [18], and supercritical fluid extraction (SFE) [19]. Most of the methods comprise two or more clean-up steps, depending on the nitrosamine, the food matrix, and the detection device, and recommend that nitrosamine formation during sample preparation should be inhibited by adding sulfamic acid, ascorbate, or other nitrosation inhibitors [20]. Several analytical methods have been employed in the past for the quantitative determination of nitrosamines in food, including colorimetry, spectrophotometry [21], polarography [22], capillary electro-chromatography [23], micellar electro-kinetic capillary chromatography [24], gas chromatography with flame ionization detection, nitrogen phosphorous detection, thermal energy detection, nitrogen chemiluminescence detection [25]-[28], and mass spectrometry detection [29]-[31], high-performance liquid chromatography with thermal energy analyzer, mass spectrometry and fluorescence detection, high-performance liquid chromatography (HPLC), chemiluminescence method, and chromatography-mass spectrometry [3] [32]. Commonly, there include identical procedures for sample preparation: extraction of $\mathrm{N}$-nitrosamines from a sample (steam or vacuum distillation), multiple extractions of $\mathrm{N}$-nitrosamines from the distillate with methylene chloride, preconcentration by evaporation, and direct analysis for chromatography-mass spectrometry and chemiluminescence method [1] [20]. No scientific papers reported using the Reverse-Phase HPLC method and direct UV detection when extracting $\mathrm{N}$-nitrosamines by autoclave treatment. However, the literature reveals a very few methods which have been published for quantification of N-nitrosamines in meat products using HPLC with direct UV detection and all the reported methods were adopting pre-column or post-column photolysis units or additional derivatization reaction to enhance the light absorbance or to get fluorescent derivatives [3] [8] [20]. First attempts to use HPLC for the determination of $N$-nitrosamines included reversed-phase HPLC with the UV detection of 7-chloro-4-nitrobenzo-2-oxa-1,3-diazole (NBD chloride), 8-methoxy-5-quinolinesulfonylaziridine (QAZ) or 5-dimethylamino-1-naphthalenesulfonyl chloride (dansyl chloride) derivatives of secondary amines obtained on the denitrosation of $N$-nitrosamines [32]. Some authors proposed to use post-column photolysis and derivatization. N-nitrosamines are separated from the sample matrix using reversed-phase liquid chromatography. The $N$-nitroso bond is cleaved by UV photolysis with the formation of nitrite ion then the nitrite is diazotized with sulfanilamide in an acid medium (according to the Griess reaction), and is then coupled with $N$-(1-naphthyl) ethylenediamine dihydrochloride (NED) to form a purple-coloured azo dye that is quantitatively determined spectrophotometrically at a maximum wavelength, $\lambda_{\max }$, of $540 \mathrm{~nm}$ [1] [32].

The aim of this work was the development of a RP-HPLC with direct UV-detection method for the determination of traces of seven volatile n-nitrosamines simultaneously from meat samples after previous autoclaving treatment [18]. The developed method was validated according to International Conference on Harmonization (ICH) guidelines to show the capability of the method [33].

\section{Methods}

\subsection{Materials}

EPA 521 nitrosamine mix standard was purchased from Supleco (USA), this solution contained seven analytes at $2000 \mu \mathrm{g} / \mathrm{mL}$ of each: N-nitrosodimethylamine (NDMA), N-nitrosomethylethylamine (NMEA), N-nitroso-diethylamine (NDEA), N-nitrosopyrrolidine (NPYR), N-nitrosodin-propylamine (NDPA), N-nitrosopiperidine (NPIP) and N-nitrosodi-n-butylamine (NDBA), and individual standards to each of the Nitrosamines with a concentration of $5000 \mu \mathrm{g} / \mathrm{mL}$ from Sigma Aldrich. For sample preparation, sodium hydroxide, ethanol, octane and dichloromethane (DCM) were purchased from Sigma-Aldrich (USA). All other chemicals (ascorbic acid, anhydrous sodium sulfate and sodium chloride) used in this research were of analytical laboratory grade aceto- 
nitrile, Methanol, and water (HPLC grade), ammonium hydroxide acid and HPLC water were obtained from Sigma Aldrich (USA). The $0.22 \mu \mathrm{m}$ PVDF syringe filter was purchased from Millipore (India). Raw meat samples purchased from local supermarkets in Damascus.

\subsection{Apparatus}

Pyrex tubes $(20 \mathrm{ml})$ with heat-stable Teflon-lined caps were used. Glass column $(30 \mathrm{~cm} \times 1.5 \mathrm{~cm})$. Kuderna Danish (KD) concentrator was used for the concentration of organic solvents. Autoclave (Selecta, Spain, 4001757). CAMAG UV Lamp dual wavelength, 254/366 nm, $2 \times 8$ watt in combination (Switzerland). KNAUER $^{\circledR}$ HPLC system (KNAUER ${ }^{\circledR}$, Germany), consisting of smart line manager, sample manager, and smartline UV detector 2500. System control, data collection, and data processing were accomplished using Eurochrom $^{\mathrm{TM}}$ chromatography data software.

\subsection{Chromatographic Conditions}

The chromatographic condition was optimized using the Knauer Symmetry C18, $5 \mu \mathrm{m}(100 \mathrm{~mm} \times 4.6 \mathrm{~mm})$ column. A solvent A is $10 \mathrm{mM}$ Ammonium hydroxide and acetonitrile as solvent B. This was then filtered through a $0.22 \mu \mathrm{m}$ PVDF membrane filter and degassed under vacuum prior to use. The separation of all components was achieved by gradient elution using solvent A and B. Solution A was used as diluent. The final selected and optimized conditions were as follows; injection volume $20 \mu \mathrm{L}$, gradient elution (solvent B from 0 to $90 \%$ during $10 \mathrm{~min}$ then maintained to the end of the run), at a flow rate of $1.0 \mathrm{~mL} / \mathrm{min}$ at $80^{\circ} \mathrm{C}$ (column oven) temperature, detection wavelength $231 \mathrm{~nm}$, and sample temperature $15^{\circ} \mathrm{C}$. Under these conditions, the backpressure in the system was about 2500 psi.

\subsection{Sample Preparation}

Extraction of N-nitrosamines was performed using the same method as our previous work [18] with a modification at the end. Approximately 6 grams of meat sample was placed in the Pyrex tube into which $10 \mathrm{~mL}$ of sodium hydroxide $1 \mathrm{~N}$ was poured. The tube was capped tightly and autoclaved at $121^{\circ} \mathrm{C}$ for $10 \mathrm{~min}$. After being allowed to stand at room temperature, the autoclaved solution was transferred to $50 \mathrm{~mL}$ separatory funnel. The tubes was rinsed twice with $5 \mathrm{~mL}$ of ethanol and then $10 \mathrm{~mL}$ of dichloromethane, and the rinsing solutions and $10 \mathrm{~mL}$ of $10 \%$ aqueous sodium chloride were combined with the original extract in the separatory funnel. After being shaken, the dichloromethane layer was collected, and the water layer was re-extracted with $10 \mathrm{ml}$ of dichloromethane. The dichloromethane extracts were combined, dried over anhydrous sodium sulfate and concentrated to approximately $0.5 \mathrm{~mL}$ using $\mathrm{KD}$ concentrator and nitrogen gas flow. The concentrate was loaded onto a silica gel column $(30 \mathrm{~cm} \times 1.5 \mathrm{~cm})$ (equilibrated with dichloromethane) and the column was eluted with $10 \mathrm{ml}$ of dichloromethane. After the addition of $100 \mu \mathrm{L}$ of octane (to prevent exsiccation of the solvent), the elute was concentrated to $1 \mathrm{~mL}$ using $\mathrm{KD}$ concentrator and nitrogen gas then extracting $3 \mathrm{~mL}$ methanol. This was repeated three times. The combined methanol extracts were concentrated to about $100 \mu \mathrm{L}$ under a nitrogen stream.

\subsection{Preparation of N-Nitrosamine Mix Standard}

A series of working standard solutions were prepared by appropriate dilution of the EPA 521 nitrosamine mix with solvent A and stored at $-20^{\circ} \mathrm{C}$ before use. From the primary stock solution $2000 \mu \mathrm{g} / \mathrm{mL}$ of each nitrosamine, a 1/50 dilution was done to get $40 \mu \mathrm{g} / \mathrm{mL}$ secondary stock solution of each nitrosamine. Sequentially dilute secondary stock solution was performed to get standards titrating at $0.5,1,2.5,5,7.5,10$, and $15 \mu \mathrm{g} / \mathrm{mL}$ in $100 \mathrm{~mL}$ volumetric flasks, these solutions kept in the absence of light.

\section{Results and Discussions}

\subsection{Method Development and Optimization}

The main criteria for development of a RP-HPLC method for the determination of seven N-nitrosamine compounds in raw meat and the method should be able to quantify all seven compounds in a single run and should be accurate, precise, linear, free of interference from blank, and enough for the routine use in quality control laboratories. Preliminary experiments were carried out until separation was achieved on C18 using injection vo- 
lume of $20 \mu \mathrm{L}$, gradient elution (solvent B from $0 \%$ to 90\% during 10 min then maintained to the end of the run), at a flow rate of $1.0 \mathrm{~mL} / \mathrm{min}$ at $80^{\circ} \mathrm{C}$ (column oven) temperature, detection wavelength $231 \mathrm{~nm}$, and sample temperature $15^{\circ} \mathrm{C}$, slight low response and some base line disturbance for nitrosamines was observed when analyzing the samples. Therefore, a slight modification on sample preparation was done by extracting the nitrosamines with methanol as mentioned in sample preparation. The peak shape and response of all nitrosamines were improved. Finally, satisfactory result was achieved in 10 minutes with flow rate of $1.0 \mathrm{~mL} / \mathrm{min}$ of the mobile phase. In order to judge the suitability of method for determining the N-nitrosodimethylamine (NDMA), N-nitrosomethylethylamine (NMEA), N-nitrosodiethylamine (NDEA), N nitrosopyrrolidine (NPYR), N-nitrosodinpropylamine (NDPA), N-nitrosopiperidine (NPIP) and N-nitrosodi-n-butylamine (NDBA) traces in meat, the method was validated as per the ICH guideline for specificity, limit of detection, limit of quantification, linearity, accuracy and precision [33]. The matrix effect was studied by comparing the slope of the aqueous standards and standard additions calibration graphs obtained for the meat samples, no statistically differences were observed, and so quantification was carried out by external calibration. Calibration curves were obtained by least squares linear regression analysis for the peak area versus the analyte concentration using six concentration levels in duplicate. The method was validated to demonstrate that it is suitable for its intended purpose by the standard procedure to evaluate adequate validation characteristics. Retention times of selected $\mathrm{N}$-nitrosamines were determined by using standard solutions of each nitrosamine. Figure 1 shows the chromatogram obtained by HPLCUV of unspiked meat sample.

\subsection{Specificity/Selectivity}

Specificity is the ability of the method to measure the analyte response in the presence of diluent. Figures 1 and 2 show that there is no interference at the RT (retention time) for all seven nitrosamine compounds due to the blank, and Table 1 shows the summery peak purity results. To assess the ability of the method, Mix standard solution were prepared with known amounts of NDMA, NMEA, NDEA, NPYR, NDPA, NPIP, NDBA, and injected into the HPLC and the chromatograms were recorded. The sample (raw meat) solution was prepared as per the methodology and injected into the chromatograph (control sample). The sample shows no peaks either due to any nitrosamines. So it reveals that the raw meat (control sample) is free from nitrosamines under investigation. Therefore the sample extract was spiked with known amount of each nitrosamine reference standard at target level $(1 \mu \mathrm{g} / \mathrm{ml})$, and injected into the chromatograph (Spiked sample). The relative retention time for NDMA, NMEA, NDEA, NPYR, NDPA, NPIP and NDBA is shown in Table 2. The resolution between the nearest compounds peak (NDPA and NDBA) was found to be 5.96 Therefore, no interference of blank was observed corresponding to any of nitrosamines. Therefore, the selectivity of the method was judged from the absence from the interfering peaks (false peaks) at the analyte elution times for blank chromatograms of different unspiked samples after irradiating them to UV light (wavelength 366 nanometer) for three hours to destroy nitrosamines if they are present [34]. The original signals were wrongly positive if the signals from the samples are not remarkably diminished after the irradiation. No matrix compounds existed that might give a false positive signal to the blank samples as shown in Figure 2.

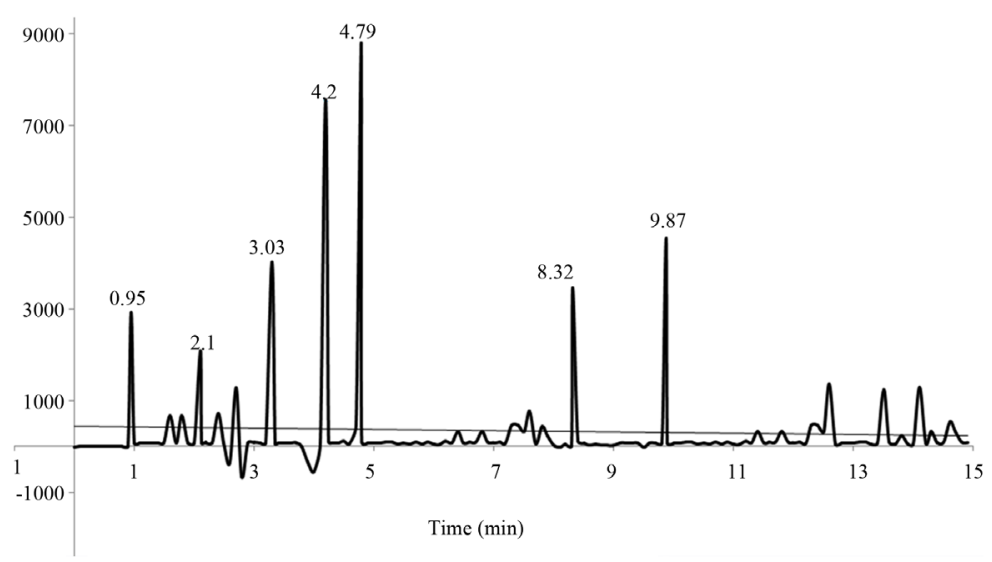

Figure 1. Chromatogram of meat sample (unspiked and before irradiating). 
Table 1. summery of peak purity results.

\begin{tabular}{cccc}
\hline Compound & RT $^{\mathrm{a}}(\mathbf{m i n})$ & resolution & Purity flag \\
\hline NDMA & 0.95 & $\mathrm{NA}^{\mathrm{b}}$ & pass \\
NMEA & 2.1 & 6.32 & pass \\
NDEA & 3.03 & 15.45 & pass \\
NDPA & 4.2 & 6.18 & pass \\
NDBA & 4.79 & 5.96 & pass \\
NPIP & 8.32 & 21.55 & pass \\
NPYR & 9.87 & 12.13 & pass \\
\hline
\end{tabular}

${ }^{\mathrm{a}}$ Retention time; ${ }^{\mathrm{b}}$ Not applicable.

Table 2. Summary of system suitability parameter.

\begin{tabular}{|c|c|c|c|c|}
\hline Nitrosamine & Theoretical plate & Tailing factor & resolution & RSD\% \\
\hline NDMA $^{\mathrm{a}}$ & 2154 & 1.1 & $N A^{h}$ & 0.56 \\
\hline NMEA $^{\mathrm{b}}$ & 2591 & 1.05 & 7.89 & 0.52 \\
\hline NDEA $^{\mathrm{c}}$ & 2236 & 1.1 & 9.45 & 0.50 \\
\hline NDPA $^{\mathrm{d}}$ & 5642 & 1.2 & 6.18 & 0.31 \\
\hline $\mathrm{NDBA}^{\mathrm{e}}$ & 6782 & 1.3 & 5.96 & 0.69 \\
\hline NPIP $^{f}$ & 7823 & 1.1 & 21.55 & 0.47 \\
\hline NPYR $^{g}$ & 9483 & 1.2 & 2.13 & 1.34 \\
\hline
\end{tabular}

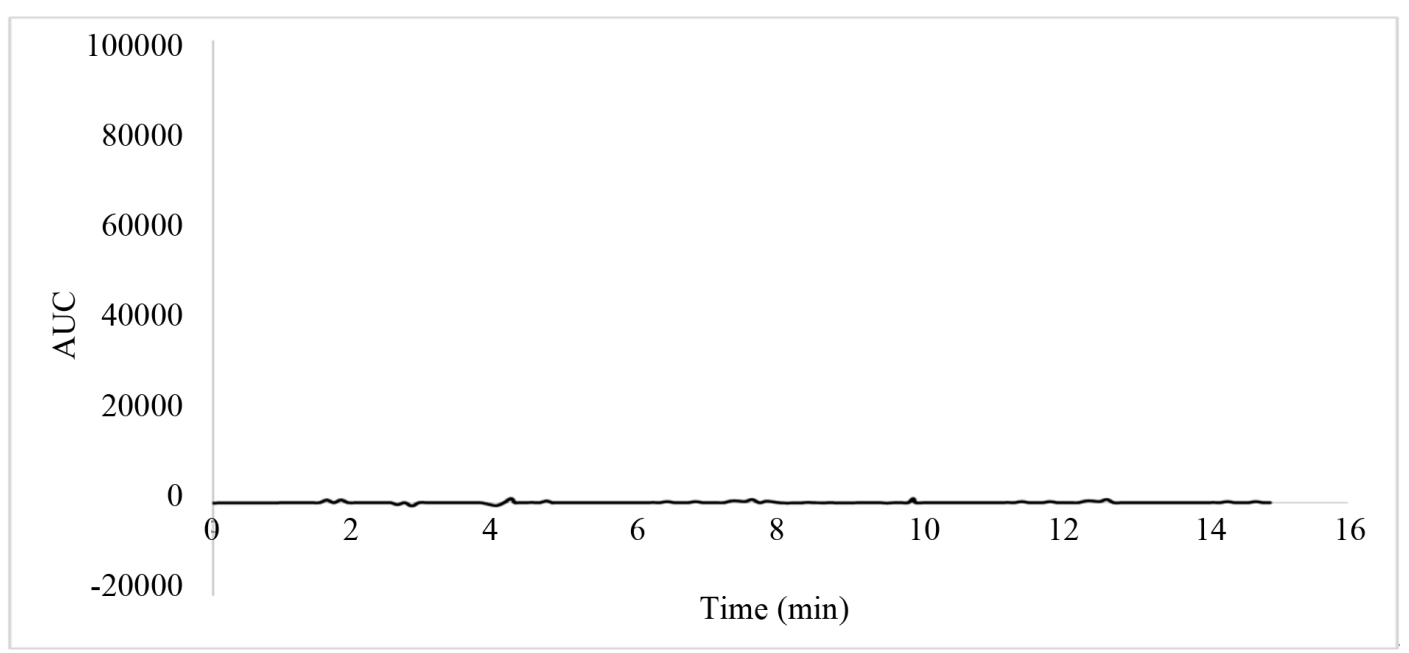

Figure 2. Chromatogram of blank (meat sample after irradiating).

\subsection{Precision}

System suitability parameters were measured to verify the system performance. System precision was determined by six replicate injections of standard preparation. Important characteristics including RSD \%, resolution (between all nearest peaks), tailing factor, and theoretical plate number were measured. The RSD \% of area 
counts of six replicate injections for all $\mathrm{N}$-nitrosamine peaks were below $2.0 \%$, and the resolution between the two nearest peaks was better than 1.5. These indicate that the system is precise and suitable for determination of all seven $\mathrm{N}$-nitrosamine compounds. The results obtained are shown in Table 2. The parameters all complied with the acceptance criteria and system suitability was established.

\subsection{Accuracy}

The accuracy of an analytical method is the closeness of test results obtained by that method compared with the true values. To confirm the accuracy of the proposed method, recovery experiments were carried out by the standard addition technique. The accuracy of the method was carried out by adding known amounts of each $\mathrm{N}$-nitrosamine corresponding to three concentration levels; $50 \%, 100 \%$, and $150 \%$ of the target concentration to the sample examined (6 grams of the sample) in triplicate. The samples were given the same treatment as described in sample preparation procedure of validation. The percentage recoveries of all components at each level and each replicate were determined. The mean of percentage recoveries $(n=3)$ and the relative standard deviation were calculated. The amount recovered was within $\pm 15.0 \%$ of the amount added, which indicates that the method is suitable for the determination of N-nitrosamines. It was confirmed from results that the method is accurate (Table 3).

\subsection{Linearity}

The linearity of an analytical method is its ability to elicit test results that are directly, or by a well-defined mathematical transformation, proportional to the concentration of the analyte in a sample within a given range. The response function was determined by preparing standard solutions at six different concentration levels ranging from $1-15 \mu \mathrm{g} / \mathrm{mL}$ for all components (LOQ to 300\% of the analyte concentration). The response was found to be linear from the $(1 \mu \mathrm{g} / \mathrm{mL})$ to $(15 \mu \mathrm{g} / \mathrm{mL})$ of the standard concentration. For all the compounds, the correlation coefficients were greater than 0.999 . The linearity concentration and the regression statistics are shown in Tables 4 and 5 respectively. Figure 3 shows the chromatogram $1 \mu \mathrm{g} / \mathrm{mL}$ standard solution of each $\mathrm{N}$-nitrosamine. The linearity curves for all components are presented in Figure 4.

\begin{tabular}{|c|c|c|c|c|}
\hline \multicolumn{2}{|c|}{ Nitrosamine } & \multirow{2}{*}{$\begin{array}{c}\text { At } 50 \% \text { level } \\
0.5 \mu \mathrm{g} / \mathrm{mL}\end{array}$} & \multirow{2}{*}{$\begin{array}{c}\text { At } 100 \% \text { level } \\
1 \mu \mathrm{g} / \mathrm{mL}\end{array}$} & \multirow{2}{*}{$\begin{array}{c}\text { At } 150 \% \text { leve } \\
1.5 \mu \mathrm{g} / \mathrm{mL} \\
89.3\end{array}$} \\
\hline & Recovery\% & & & \\
\hline & $\mathrm{RSD}^{\mathrm{a}}$ & 2.5 & 2.2 & 2.7 \\
\hline \multirow{2}{*}{ NMEA } & Recovery\% & 81 & 85.3 & 83.60 \\
\hline & RSD\% & 2.32 & 2.89 & 2.54 \\
\hline \multirow{2}{*}{ NDEA } & Recovery\% & 81.8 & 79.1 & 83.4 \\
\hline & RSD\% & 2.2 & 2.2 & 2.7 \\
\hline \multirow{2}{*}{ NDPA } & Recovery\% & 86.1 & 89.1 & 81.2 \\
\hline & RSD\% & 1.3 & 2.6 & 2.7 \\
\hline \multirow{2}{*}{ NDBA } & Recovery\% & 88.9 & 87.5 & 82.3 \\
\hline & RSD\% & 1.9 & 2.1 & 2.5 \\
\hline \multirow{2}{*}{ NPIP } & Recovery\% & 81.8 & 77.6 & 91.4 \\
\hline & RSD\% & 2.1 & 2.7 & 2.5 \\
\hline \multirow{2}{*}{ NPYR } & Recovery\% & 91.2 & 85.9 & 86.1 \\
\hline & RSD\% & 2.7 & 2.9 & 2.2 \\
\hline
\end{tabular}

${ }^{\mathrm{a}}$ Relative standard deviation. 
Table 4. Linearity concentrations.

\begin{tabular}{ccc}
\hline Series Number & Sample ID & Concentration $\mu \mathrm{g} / \mathrm{mL}$ \\
\hline $\mathbf{1}$ & LOQ Solution & 1 \\
$\mathbf{2}$ & $50 \%$ of linearity level & 2.5 \\
$\mathbf{3}$ & $100 \%$ of linearity level & 5 \\
$\mathbf{4}$ & 150\% of linearity level & 7.5 \\
$\mathbf{5}$ & 200\% of linearity level & 10 \\
$\mathbf{6}$ & $300 \%$ of linearity level & 15 \\
\hline
\end{tabular}

Table 5. Linearity Statistics.

\begin{tabular}{cccc}
\hline Compound & $\begin{array}{c}\text { Linearity Range } \\
(\mu \mathrm{g} / \mathrm{mL})\end{array}$ & $\begin{array}{c}\text { Correlation } \\
\text { Coefficient } \mathrm{R}^{2}\end{array}$ & Linearity Equation \\
\hline NDMA & $1.02-15.30$ & 0.9998 & $\mathrm{y}=4804.1 \mathrm{x}-105.69$ \\
NMEA & $1.02-15.54$ & 0.9999 & $\mathrm{y}=6122.8 \mathrm{x}-105.69$ \\
NDEA & $1.04-15.53$ & 0.9997 & $\mathrm{y}=4954 \mathrm{x}+189.51$ \\
NDPA & $1.04-15.53$ & 0.9999 & $\mathrm{y}=10287 \mathrm{x}+227.23$ \\
NDBA & $1.05-15.75$ & 0.9989 & $\mathrm{y}=11098 \mathrm{x}+229.09$ \\
NPIP & $1.03-15.45$ & 0.9998 & $\mathrm{y}=5096.4 \mathrm{x}+61.356$ \\
NPYR & $1.02-15.30$ & 0.9999 & $\mathrm{y}=12444 \mathrm{x}+257.85$
\end{tabular}

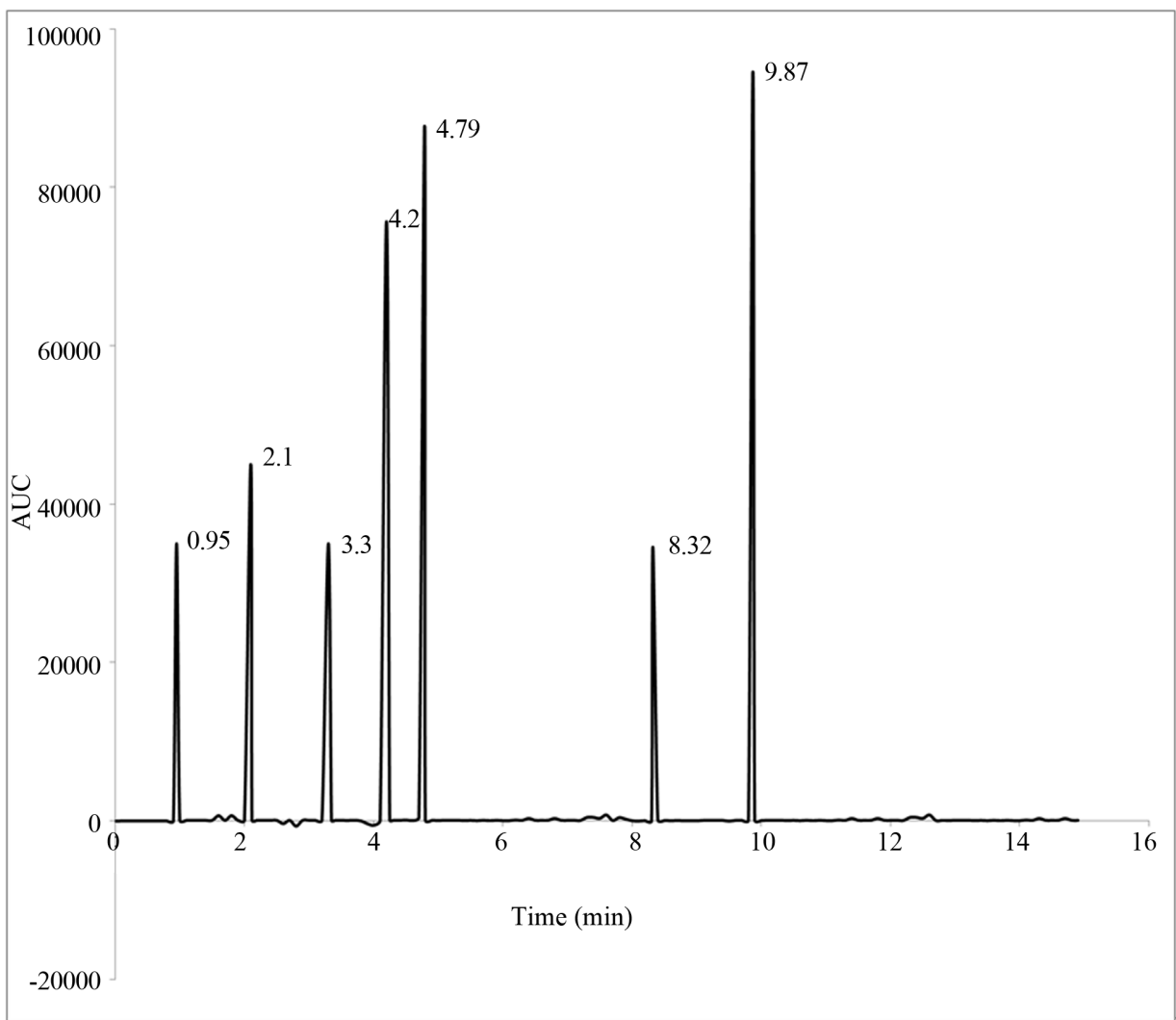

Figure 3. Chromatogram of composite $\mathrm{N}$-nitrosamines standard ( $1 \mu \mathrm{g} / \mathrm{ml}$ of each nitrosamine). 

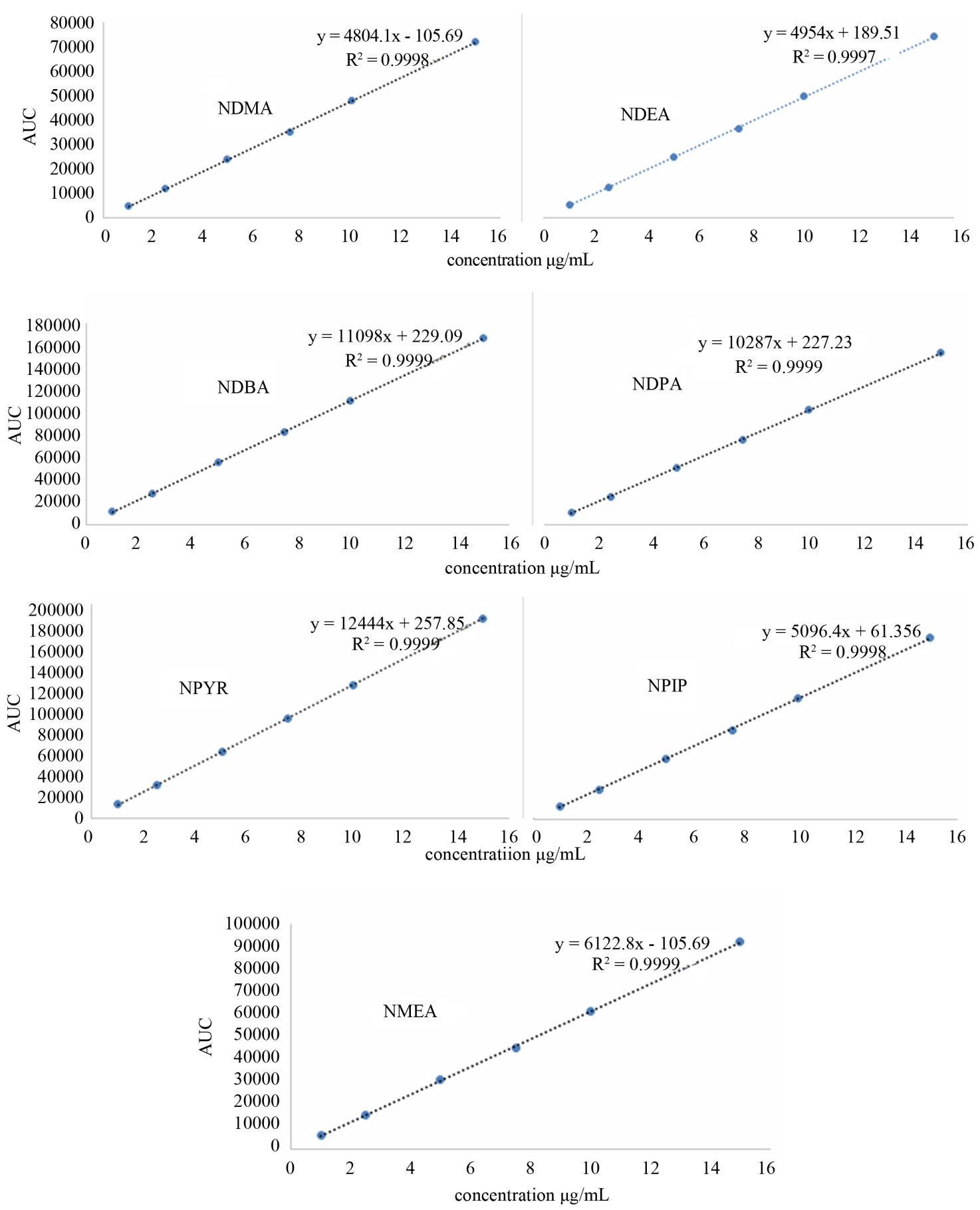

Figure 4. Linearity curves of tested N-nitrosamines.

\subsection{Limit of Quantification (LOQ) and Limit of Detection (LOD)}

The signal-to-noise ratio $(\mathrm{S} / \mathrm{N})$ method was adopted for the determination of the lower limit of quantification. The limit of quantification is estimated to be ten times the $\mathrm{S} / \mathrm{N}$ ratio, limit of detection is estimated to be three times of $\mathrm{S} / \mathrm{N}$ ratio. The quantification limit was achieved by injecting a series of possible dilute solutions of all components and the precision was established at the quantification level. The RSD \% of peak areas was well within the acceptance limit, not more than $10 \%$. The determined lower limit of qualification and precision at LOQ values for all components are presented in Table 6. 
Table 6. LOQ and LOQ precision.

\begin{tabular}{cccc}
\hline Compound & LOQ $(\mu \mathrm{g} / \mathrm{mL})$ & LOD $(\mu \mathrm{g} / \mathrm{mL})$ & Precision $(\mathrm{RSD} \%)$ \\
\hline NDMA & 1.616 & 0.48 & 0.5 \\
NDEA & 2.029 & 0.61 & 0.75 \\
NDPA & 1.097 & 0.33 & 0.43 \\
NDBA & 1.550 & 0.46 & 1.77 \\
NPIP & 1.011 & 0.30 & 1.73 \\
NPYR & 1.775 & 0.53 & 1.63 \\
\hline
\end{tabular}

\subsection{Sample Results}

Meat samples were treated with $1 \mathrm{~N} \mathrm{NaOH}$ for 10 min in autoclaved conditions and then analyzed by HPLC-UV and the results of 25 samples of different meat products which examined for the evaluation of the analytical method shows the presence of some volatile nitrosamine in all different products, and the absence of NMEA NDPA, and NDBA in 5 sample tested which may related to the presence of these three nitrosamines in low amounts which may below under the quantitation limit of our procedure, or the real absence of these nitrosamine in the sample tested. Statistically when applying (PASW Statistics 18) one way ANOVA test for statistical comparisons between the means of sum of seven nitrosamines in meat samples, there was significant difference ( $\mathrm{p}<$ 0.05 ) which may related to the low number of samples, or because that some of tested samples are may be preserved by nitrite salts which contributing in nitrosamine formation in meat. The average sum of the N-nitrosamine found was in the range of 3.3 to $7 \mu \mathrm{g} / \mathrm{kg}$ of meat samples.

\section{Conclusion}

A gradient RP-HPLC method was successfully developed for the estimation of seven volatile N-nitrosamines in the meat products in single determination. The method validation results proved that the method is precise, accurate, and linear and could be applied in combination with autoclaving treatment for sample preparation in estimation of $\mathrm{N}$-nitrosamines in meat for monitoring food safety.

\section{References}

[1] Nawrocki, J. and Andrzejewski, P. (2011) Nitrosamines and Water. Journal of Hazardous Materials, 189, 1-18. http://dx.doi.org/10.1016/j.jhazmat.2011.02.005

[2] Mlongo, S.H., Mamba, B.B. and Krause, R.W. (2009) Nitrosamines: A Review on Their Prevalence as Emerging Pollutants and Potential Remediation Options.

http://www.wrc.org.za/Knowledge\%20Hub\%20Documents/Water\%20SA\%20Journals/Manuscripts/2009/05\%20Octo ber/2393.pdf

[3] Bellec, G.F., Cauvin, M.C., Calve, K.L., Dreano, Y., Gouerou, H., Menez, J.F. and Berthou, F. (1996) Analysis of NNitrosamines by High-Performance Liquid Chromatography with Post-Column Photohydrolysis and Colorimetric Detection. Journal of Chromatography A, 727, 83-92. http://dx.doi.org/10.1016/0021-9673(95)01073-4

[4] Schothorst, R.C. and Somers, H.H.J. (2005) Determination of N-Nitrosodiethanolamine in Cosmetic Products by LC-MS-MS. Analytical and Bioanalytical Chemistry, 381, 681-685. http://dx.doi.org/10.1007/s00216-004-2914-5

[5] Wang, X., Gao, Y., Xu, X., Zhao, J., Song, G. and Hu, Y. (2011) Derivatization Method for Determination of Nitrosamines by GC-MS. Chromatographia, 73, 321-327. . http://dx.doi.org/10.1007/s10337-010-1871-8

[6] Joossens, J.V., Hill, M.J., Elliott, P., Stamler, R., Stamler, J., Lesaffre, E., Dyer, A., Nichols, R. and Kesteloot, H. (1996) Dietary Salt, Nitrate and Stomach Cancer Mortality in 24 Countries. International Journal of Epidemiology, 25, 494-504.

[7] Rywotycki, R. (2003) Meat Nitrosamine Contamination Level Depending on Animal Breeding Factors. Meat Science, 65, 669-676.

[8] Cardenes, L., Ayala, J. H., Gonzalez, V. and Alfonso, A.M. (2002) Fast Microwave-Assisted Dansylation of N-Nitrosamines Analysis by High-Performance Liquid Chromatography with Fluorescence Detection. Journal of Chromatography $A, \mathbf{9 4 6}, 133-140$. 
[9] Ventanas, S. and Ruiz, J. (2006) On-Site Analysis of Volatile Nitrosamines in Food Model Systems by Solid-Phase Micro-Extraction Coupled to a Direct Extraction Device. Talanta, 70, 1017-1023.

[10] Yurchenko, S. and Molder, U. (2007) The Occurrence of Volatile N-Nitrosamines in Estonian Meat Products. Food Chemistry, 100, 1713-1721.

[11] Ramos, A.M., Orazio, G.D., Borges, J.H., Rocco, A. and Fanali, S. (2011) Multi-Walled Carbon Nano-Tubes-Dispersive Solid-Phase Extraction Combined with Nano-Liquid Chromatography for the Analysis of Pesticides in Water Samples. Analytical and Bioanalytical Chemistry, 400, 1113-1123.

[12] Planas, C., Palacios, O., Ventura, F., Rivera, J. and Caixach, J. (2008) Analysis of Nitrosamines in Water by Automated SPE and Isotope Dilution GC/HRMS Occurrence in the Different Steps of a Drinking Water Treatment Plant, and in Chlorinated Samples from a Reservoir and a Sewage Treatment Plant Effluent. Talanta, 76, 906-913.

[13] Association of Official Analytical Chemists (1990) N-Nitrosamines (Volatile) in Fried Bacon. Mineral Oil Vacuum Distillation-Thermal Energy Analyzer Method. No. 982.22, Official Methods of Analysis, 15th Edition.

[14] Greenfield, E.L., Smith, W.J. and Malanovski, A.J. (1982) Mineral Oil Vacuum Distillation for Nitrosamines in Fried Bacon, with Thermal Energy Analyser. Journal of the Association Official Analytical Chemists, 65, 1319-1332.

[15] Telling, G.M., Bryce, T.A. and Althorpe, J.J. (1971) Use of Vacuum Distillation and Gas Chromatography-Mass Spectrometry for Determining Low Levels of Volatile Nitrosamines in Meat Products. Journal of Agricultural and Food Chemistry, 19, 937-940. http://dx.doi.org/10.1021/jf60177a011

[16] Raoul, S., Gremaud, E., Biaudet, H. and Tureski, R. (1997) Rapid Solid-Phase Extraction Method for the Detection of Volatile Nitrosamines in Food. Journal of Agricultural and Food Chemistry, 45, 4706-4713. http://dx.doi.org/10.1021/jf970232q

[17] Ventanas, S., Martín, D., Estévez, M. and Ruiz, J. (2006) Analysis of Volatile Nitrosamines from a Model System Using SPME-DED at Different Temperatures and Times of Extraction. Food Chemistry, 99, 842-850. http://dx.doi.org/10.1016/j.foodchem.2005.08.035

[18] Al-kaseem, M., Assaf, Z. and Karabeet, F. (2013) Rapid and Simple Extraction Method for Volatile N-Nitrosamines in Meat Products. Pharmacology \& Pharmacy, 4, 611-618. http://dx.doi.org/10.4236/pp.2013.48087

[19] Fiddler, W. and Pensabene, J.W. (1996) Supercritical Fluid Extraction of Volatile N-Nitrosamines in Fried Bacon and Its Drippings: Method Comparison. Journal of AOAC International, 79, 895-901.

[20] Nollet, M.L. and Toldra, F. (2009) Handbook of Processed Meats and Poultry Analysis. In: Rath, S. and Reyes, F.G.R., Eds., Nitrosamines, Taylor \& Francis Group, New York, 687-702.

[21] Qiang, M., Wei, X.H., Chao, W., Hua, B., Cheng, X.G., Ning, S., Yan, X.L. and Bing, W.J. (2011) Determination of Ten Volatile Nitrosamines in Cosmetics by Gas Chromatography Tandem Mass Spectrometry. Chinese Journal of Analytical Chemistry, 39, 1201-1207. http://dx.doi.org/10.1016/S1872-2040(10)60466-5

[22] Walters, C.L., Johnson, E.M. and Ray, N. (1970) Separation and Detection of Volatile and Non-Volatile N-Nitrosamines. Analyst, 95, 1970.

[23] Matyska, M.T., Pesek, J.J. and Yang, L. (2000) Screening Method for Determining the Presence of N-Nitrosodiethanolamine in Cosmetics by Open-Tubular Capillary Electrochromatography. Journal of Chromatography A, 887, 487-503. http://dx.doi.org/10.1016/S0021-9673(00)00451-9

[24] Filho, P.J.S., Valcarcel, M., Rios, A., Zanin, K.D. and Caramoa, E.B. (2003) Determination of Nitrosamines in Preserved Sausages by Solid-Phase Extraction-Micellar Electro-Kinetic Chromatography. Journal of Chromatography A, 985, 503-512.

[25] Grebel, J.E. and Suffet, H.I. (2007) Nitrogen-Phosphorus Detection and Nitrogen Chemiluminescence Detection of Volatile Nitrosamines in Water Matrices: Optimization and Performance Comparison. Journal of Chromatography A, 1175, 141-144. http://dx.doi.org/10.1016/j.chroma.2007.09.073

[26] Ozel, M.Z., Gongus, F., Yagci, S., Hamilton, J.F. and Lewis, A.C. (2010) Determination of Volatile Nitrosamines in Various Meat Products Using Comprehensive Gas Chromatography-Nitrogen Chemiluminescence Detection. Food and Chemical Toxicology, 48, 3268-3273. http://dx.doi.org/10.1016/j.fct.2010.08.036

[27] Hfiger, B. and Niessner, R. (1996) Determination of N-Nitrosomethylaniline and Methylaniline in the Gas Phase. Microchimica Acta, 122, 35-44. http://dx.doi.org/10.1007/BF01252403

[28] Incavo, J.A. and Schafer, M.A. (2006) Simplified Method for the Determination of N-Nitrosamines in Rubber Vulcanizates. Analytica Chimica Acta, 557, 256-261. http://dx.doi.org/10.1016/j.aca.2005.10.018

[29] Tsikas, D. (2005) Methods of Quantitative Analysis of the Nitric Oxide Metabolites Nitrite and Nitrate in Human Biological Fluids. Free Radical Research, 39, 797-815. http://dx.doi.org/10.1080/10715760500053651

[30] Dallinga, J.W., Pachen, D.M., Lousberg, A.H., Van Geel, J.A., Houben, G.M., Stockburgger, R.W., Maanen, J.M. and Kleinjans, J.C. (1998) Volatile N-Nitrosamines in Gastric Juice of Patients with Various Conditions of the Gastrointes- 
tinal Tract Determined by Gas Chromatography-Mass Spectrometry and Related to Intragastic pH and Nitrate and Nitrite Levels. Cancer Letters, 124, 119-125. http://dx.doi.org/10.1016/S0304-3835(97)00467-9

[31] Xia, Y., McGuffey, J.E., Bhattacharyya, S., Sellergren, B., Yilmaz, E. and Wang, L. (2005) Analysis of the TobaccoSpecific Nitrosamine 4-(Methylnitrosamino)-1-(3-Pyridyl)-1-Butanol in Urine by Extraction on a Molecularly Imprinted Polymer Column and Liquid Chromatography/ Atmospheric Pressure Ionization Tandem Mass Spectrometry. Analytical Chemistry, 77, 7639-7645. http://dx.doi.org/10.1021/ac058027u

[32] Komarova, N.V. and Velikanov, A.A. (2001) Determination of Volatile N-Nitrosamines in Food by High-Performance Liquid Chromatography with Fluorescence Detection. Journal of Analytical Chemistry, 56, 359-363. http://dx.doi.org/10.1023/A:1016652213062

[33] (2005) International Conference on Harmonization, Validation of Analytical Procedure, Text and Methodology Q2 (R1), IFPMA, Geneva.

[34] BS ISO 29941 (2010) Condoms-Determination of Nitrosamines Migrating from Natural Rubber Latex Condoms. International Standards. 